\title{
Teaching Historical Literacy within a SOTL Framework
}

Peter Burkholder

Fairleigh Dickinson University

The Scholarship of Teaching and Learning (SoTL) posits that educators can, and should, approach educational matters with the same rigor used to examine traditional fields of inquiry. In the SoTL approach, one identifies a learning problem, formulates methods to address it, gathers actual evidence of students' progress, then shares findings with the broader academic community. ${ }^{1}$ Also like traditional research, SoTL situates teaching and learning within theoretical frameworks. My workshop at the 2019 American Historical Association conference stressed this latter aspect, using textual analysis as an example. Simply put: We can devise more effective reading techniques, and we can better evaluate their results, if we understand some theories and findings surrounding learning and historical reading skills. The goal of this short article is to introduce readers to some of those constructs and to offer some rudimentary techniques that instructors can implement as part of a SoTL approach to improved historical literacy.

Three key concepts are especially useful as a foundation here. The first, "learning bottlenecks," draws attention to inherent points of difficulty that students must work through when faced with an unfamiliar task. ${ }^{2}$ In the case of reading documents from the past, a common bottleneck is that such artifacts often cannot be read at face value but must be carefully analyzed and contextualized in

1 See the pioneering article by Randy Bass, "The Scholarship of Teaching:

What's the Problem?" Inventio 1, no. 1 (1999): < https://my.vanderbilt.edu/sotl/ files/2013/08/Bass-Problem1.pdf $>$.

2 Joan Middendorf and Leah Shopkow, Overcoming Student Learning Bottlenecks (Sterling, VA: Stylus, 2018).

(C) 2019 Burkholder. Free to copy and share for education and scholarship under a Creative Commons Attribution NonCommercial-NoDerivatives 4.0 License. 
order to reveal deeper meaning. The second concept, "decoding," is a metacognitive exercise involving the careful examination of what an expert does to get through a given bottleneck. ${ }^{3}$ By identifying the many, often subconscious steps involved in the reading process, an instructor is in a better position to guide students through the stages of extracting both explicit and implicit information from a text. To operationalize that process involves the third concept of "deliberate practice," or the specific activities students must partake in, based on decoding, to clear a learning bottleneck. This is the phase where significant learning can occur, because it often challenges students' natural tendencies and assumptions, and because it is focused on clearly delineated steps that learners must take for increased understanding. Of note is that deliberate practice is hard work. Its leading advocate, psychologist Anders Ericsson, has determined that this type of activity is not enjoyable and requires the guidance and feedback of an expert for improvement. ${ }^{4}$

To see how these concepts can be brought together to help our learners, one can imagine the following scenario: It is the end of class, and the instructor reminds students that for homework, they need to read a textbook chapter, a journal article, a popular website column, and a primary source. As an experienced professional, the instructor understands that these readings were created for different audiences and different purposes and thus must be read in unique ways. But to many students, it is all likely just words on a page or screen, and their job is to read for content and memorize as much of it as possible. Research on the reading habits of experts and non-experts has shown this lack of source differentiation to be but one major difference between the two groups. ${ }^{5}$

\footnotetext{
3 David Pace, The Decoding the Disciplines Paradigm (Bloomington: Indiana University Press, 2017).

4 K. Anders Ericsson, Peak: Secrets from the New Science of Expertise (Boston: Houghton Mifflin Harcourt, 2016).

5 Sam Wineburg, Historical Thinking and Other Unnatural Acts: Charting the Future of Teaching the Past (Philadelphia: Temple University Press, 2001),
} 
A learning bottleneck thus presents itself, probably unbeknownst to the aforesaid imagined students and their homework. As an expert, what exactly does the instructor do to get through it? (This is the decoding part.) And can the teacher devise exercises to reinforce deeper, more appropriate reading techniques? (There is the deliberate practice.) These are deceptively difficult questions to answer or even be aware of because seasoned professionals suffer from the so-called "curse of knowledge," which blinds them to problems that non-experts face. ${ }^{6}$

A blunt-force approach of having students read more and more texts will not work here - in fact, it could have the unintended effect of reinforcing inadequate extant habits. Socalled "coverage" courses, which operate under the assumption that history is an assembly of agreed-upon facts which students are expected to master, advocate blunt-force: Simply put, more materials and content is perceived as better for learning. ${ }^{7}$ The frequency of the coverage approach, even at the college level, as

especially ch. 3, "On the Reading of Historical Texts." See also Peter Burkholder, "Why You Read Like an Expert - and Why Your Students Probably Don't," Faculty Focus (November 17, 2014): <https://www.facultyfocus.com/articles/ teaching-and-learning/read-like-expert-students-probably-dont/>.

6 On the "curse," Steven Pinker, The Sense of Style (New York: Viking, 2014), 59. Its broader implications for teaching and learning are delineated in Nancy Schorschinsky, "Coping with the Curse of Knowledge (and Yes, You May Have It Too)," The Teaching Professor (September 23, 2019): <https://www. teachingprofessor.com/topics/professional-growth/reflections-on-teaching/ coping-with-the-curse-of-knowledge-and-yes-you-may-have-it-too/>.

7 On coverage, see Lendol Calder, "Uncoverage: Toward a Signature Pedagogy for the History Survey," Journal of American History 92, no. 4 (2006), 1358-1370. On the fallacy of more content equating with increased learning, see Maryellen Weimer, Learner-Centered Teaching: Five Key Changes to Practice, $2^{\text {nd }}$ edition (San Francisco: Jossey-Bass, 2013), 115. On non-experts' belief that history is primarily an assembly of facts as opposed to interpretation, see Peter Burkholder and Krista Jenkins, "What Are Our Fields About? Survey Suggests Disconnect between Professionals and the Public," The Teaching Professor (forthcoming, 2019). 
well as its shortcomings, have been well documented. ${ }^{8}$ The fallacy of increased reading volume resulting in better literacy skills is thus all the more true here, since cognitive psychology informs us that the most important factor in effective studying is not timeon-task, or a genuine desire to learn, or studying in a way that matches one's so-called "learning style" (in fact, researchers can find no evidence for the existence of such styles). Rather, the key to improved studying is what one thinks about while one studies, meaning students need a deliberate practice reading framework to approach different types of historical texts productively. ${ }^{9}$

Such frameworks are readily available, though they take considerable time, concentration, and practice in which to gain competence, and they must be conveyed to learners in a comprehensible and supportive fashion. One approach is for experts to model how they, as seasoned professionals, read various types of texts, demonstrating in "real time" how they make sense of them. This is the "think-aloud" protocol, developed by Sam Wineburg to catch professionals and their students in the very act of thinking - something that learners often are unaware of and rarely ever see from their instructors. The main stipulation is that, while reading any type of text aloud, the reader has to vocalize everything that comes to mind as it happens. This unveils the

8 Joel Sipress and David Voelker estimate that coverage remains popular, if not dominant, in college-level history courses in the United States; Joel M. Sipress and David J. Voelker, "From Learning History to Doing History," in Exploring Signature Pedagogies: Approaches to Teaching Disciplinary Habits of Mind, eds. Regan A. R. Gurung, Nancy L. Chick, and Aeron Haynie (Sterling, VA: Stylus, 2009), 19-35.

9 Stephen Chew, "Helping Students Get the Most Out of Studying," in Applying Science of Learning in Education: Infusing Psychological Science into the Curriculum, eds. Victor Benassi, Catherine Overson, and Christopher M. Hakala (Society for the Teaching of Psychology, 2014), 215-223. See also Samford University, "How to Get the Most Out of Studying, Episode 2: 'What Students Should Know about How People Learn," YouTube Video, 7:14, August 16, 2011, https://www.youtube.com/watch?v=907y7XEC66M. 
"mock reader," who questions, interrogates, doubts, and crossreferences texts, as opposed to simply accepting their veracity and mining them for raw content. After demonstrating the process, an instructor's students can mimic it in small groups with a selected text. It can be an awkward and challenging exercise at first, but it is precisely the type of deliberate practice that, if continued over time and with helpful guidance, can lead to an appreciation for disparate types of texts, as well as their meta-content. ${ }^{10}$ The urgency for such work is seen in recent research showing that even college-level students, untrained in targeted reading techniques, perform poorly at differentiating and analyzing historical texts and artifacts. ${ }^{11}$

A second protocol, which can be used in tandem with or as an alternative to the one above, is to provide students with question sets that help steer readers toward modes of thinking that are conducive to deeper understandings of texts, as well as ways to differentiate them. Such questions lay bare the heuristics - the mental shortcuts - that experts use when confronting written history. As such, they are not geared toward content, per se; rather, they revolve around three facets of analysis that Wineburg detected in experts: sourcing (e.g., who created the document and why; how distant the source is from the events described; reasons to suspect ulterior motives), cross-checking (e.g., whether other readings tell similar or different versions of events), and, in the case of primary sources, imagining the setting (i.e., matters pertaining to historical empathy). ${ }^{12}$ Answering such questions methodically

10 On the think-aloud technique, see Wineburg, Historical Thinking, ch. 3; more recently, see Sam Wineburg, Why Learn History (When It's Already on Your Phone) (Chicago: University of Chicago Press, 2018), ch. 4.

11 Sam Wineburg, Mark Smith, and Joel Breakstone, "What Is Learned in College History Classes?" Journal of American History 104, no. 4 (March 2018); 983-993. 12 Question sets designed around the three headings of sourcing, cross-checking, and imagining the setting have been distributed during readings of the Advanced Placement World History exam and are reproduced in Cynthia Boyle et al., Document-Based Assessment Activities (Huntington Beach, CA: Shell Education, 2010), 7. 
is disorienting, time-consuming, and labor-intensive for learners who, as described above, often see the field of history as one of content acquisition, not interpretation. The protocol can even challenge students' assumptions about what it means to be literate, insofar as their present skills may have served them well up to that point. ${ }^{13}$ But the approach breaks down a complex reading process into discrete steps that are more manageable, allowing learners, with sufficient practice and feedback, to clear a critical learning bottleneck. It is precisely the sort of deliberate practice needed to bring students to a more nuanced and sophisticated appreciation of the past through textual analysis, but it may call for an altogether different approach to teaching the past.

Consistent with SoTL practices, each of two methods outlined above can then be employed to gather firm evidence about students' learning and the bottlenecks they face. Which aspect of analysis - sourcing, cross-checking, or imagining the setting - is the most challenging? If students' question set responses are coded and then quantified for frequencies, what trends appear in their answers, and how can we use them as guides to better instruction? In the case of think-alouds, one crude but telling measure is to have students time their peers' efforts, and then compare the results against the instructor's. Students are often surprised: They assume that experts analyze much more quickly than nonexperts, but the opposite is more often the case - perhaps by a wide margin. ${ }^{14}$ A simple, ongoing and quantifiable gauge of students' reading proficiencies is thus whether their think-aloud efforts become longer (and by how much) as they get more practice and feedback. And because both of these protocols require repeated efforts, they carry the added benefit of getting processes into long-

13 Ken Bain calls such challenges "expectation failures," where one's skills and frameworks for understanding collapse. See Ken Bain, What the Best College Teachers Do (Cambridge, MA: Harvard University Press, 2004), 28.

14 On experts slowing down like this, see Wineburg, Historical Thinking, 69-70. My own experiments show that I usually take about three times longer to perform a think-aloud than most of my students. 
term memory so that they can be used in working memory - the site where actual thinking occurs. ${ }^{15}$

Sharing the methods and results of such protocols is at the core of SoTL research. Moreover, by placing learning evidence about students' reading and analysis skills within the theoretical frameworks noted earlier, scholars have greater explanatory powers - just as is the case with our traditional historical research. Learning successes (or failures) thereby move from being idiosyncratic and impressionistic to carefully planned and supported by both theory and data. That is a major shift in professional practice, not unlike what we seek to instill in our students when we push them to make evidence-based arguments. Although it may require an overhaul of how we conceive of and teach our subject, it places the educational emphasis where it should be: on helping the learner acquire a deeper, more authentic understanding of the past. ${ }^{16}$

15 On this process, see the work of cognitive psychologist Daniel Willingham, Why Don't Students Like School? (San Francisco: Jossey-Bass, 2009), 13-18. 16 This last point leads into effective course design, which is beyond the purview of this article; for a brief introduction, see Peter Burkholder, "Backward Design, Forward Progress," Faculty Focus (December 5, 2018): < https://www.facultyfocus. com/articles/course-design-ideas/backward-design-forward-progress/>. For further discussion of matters involving the assessment of learning in history, readers would be well served by consulting Lendol Calder and Tracy Steffes, "Measuring College Learning in History," in Improving Quality in American Higher Education: Learning Outcomes and Assessments for the $21^{\text {st }}$ Century, eds. Richard Arum, Josipa Roksa, and Amanda Cook (San Francisco: Jossey-Bass, 2016), 37-86. 